\title{
Nurses ' knowledge and Attitudes about Mental Illness in Mental Health and General Hospitals in Tanta
}

\author{
Nahed Ahmed Morsy, \\ Assisstant professor of Psychiatric and Mental Health Nursing \\ Faculty of Nursing, Tanta University \\ Mervat Hosny Shalaby, \\ Lecturer of Psychiatric and Mental Health Nursing \\ Faculty of Nursing, Tanta University \\ Souzan Abd Elmenem Abd Elghafar, \\ Clinical Demonstrator of Psychiatric and Mental Health Nursing \\ Faculty of Nursing, Tanta University
}

\begin{abstract}
The magnitude of mental health problems is considerable. Studies have shown that there is a negative attitude towards mental illness among medical professionals both in mental health services and other health services as well as general population .Such negative attitudes can have detrimental effect on the mentally ill person's ability to find access to services, level of support they receive, type of treatment, development of effective care, and hence their recovery rate. This study aimed to assess the level of nurses' knowledge and to determine their attitudes towards mental illness in mental health and general hospitals .This study followed a descriptive design. The study was carried out at "Tanta Mental Health Hospital ", " Psychiatric department of Tanta University Hospital "and " Tanta University Students' Hospital. The subjects of the study consisted of 280 nurses working in the previous hospitals .Two tools were used to collect data for the study: first, the questionnaire sheet concerning knowledge about mental illness and second, the community Attitudes towards Mental Illness scale (CAMI). The results revealed, a significant difference between nurses working in mental health hospital and nurses working in general hospital regarding their knowledge and attitudes towards mental illness. Nurses working in mental health hospital had a better knowledge and more positive attitudes than those working in general hospital. The study recommended that, In-service training and educational program for all nurses should be implemented to provide better understanding about the nature of mental illness. Strategies in nursing education should concentrate on the affective domain and communication skills to enhance attitude shaping.
\end{abstract}




\section{Introduction}

Mental illnesses are common cause of disability and impaired quality of life in community settings ${ }^{(1)}$. While there is debate over how to define mental illness, it is generally accepted that mental illness involve disturbance of thoughts, behaviors, and emotions serious enough to cause functional impairment in people, making them more difficult to sustain interpersonal relationships and carry on their jobs, and sometimes leading to self-destructive behavior and even suicide (2). The American Psychiatric Association (APA) defines mental illness or disorder as a clinically significant behavioral or psychological syndrome experienced by a person and marked by distress, disability, risk of suffering, or loss of freedom. The symptoms of disorder must be above and beyond expected reactions to an every day event and the syndrome is not merely a cultural expectation ${ }^{(3,4)}$.

The specific causes of mental illness are unknown. Multiple factors involving genetic predispositions and environmental influences such as stress and unhealthy life style often contribute to the development of mental illness. ${ }^{(5)}$ Moreover, there are many myths or misconceptions about the mental illness such as being not a true illness that is caused by personal weakness,
God's punishment, and/or evil spirit. The mentally ill may be viewed as violent, danger ----------etc ${ }^{(6)}$

Due to these misunderstanding and myths surrounding mental illness, the mentally ill are stigmatized. The concept of stigmatization has been described and operationalized by many researchers. In modern times stigma has often been used to denote some form of community sanction that make an individual as being unacceptably different from the general population with whom he or she interacts which threaten individual's self esteem and identity. ${ }^{(7,8)}$

The topic of mental illness itself evokes a feeling of embarrassment, fear or even disgust fostering negative attitude towards mental illness and the mentally ill ${ }^{(9)}$

A large body of research has documented that general public view about mental illness remains largely unfavorable. ${ }^{(9,10,11)}$ Other studies show that nurses are also prone to the same misconceptions as the public. At times nurses working in mental hospitals are expecting mentally ill patients to be hostile, violent, immature, while those working in general hospitals may elicit negative attitude like fear and violence $^{(11)}$ Many professionals had the 
idea that clients with mental illness must be protected from real

life, as they couldn't have jobs, careers, college degrees apartments, or homes.$^{(12)}$ So the current attitudes of who provide services to those with emotional problems are important to understand as well. ${ }^{(10)}$

Attitudes influence both professional and personal behavior, in particular stigma associated with mental illness and expressed by mental health professionals as well as general public has a detrimental effect on a mentally ill person's ability to find access to services, level of support received, type of treatment, and development of effective care and recovery. ${ }^{(13,14)}$

McLaughlin (1994) maintained that a person's attitude toward another person involves a disposition to react favorably or unfavorably to that person. ${ }^{(15)}$. According to some social psychologists an attitude has three components; the Cognitive component consists of one's thoughts, beliefs, and ideas about something. When a human being is the object of an attitude, the cognitive component is frequently a stereotype, e.g. "the mentally ill are dangerous". The affective component also known as the feeling component because it refers to the feelings or emotions that something evokes such as fear, sympathy, and hate. e.g. "I'm frightened of the mentally ill". Conative, or behavioral component includes a tendency or disposition to act in certain ways toward something. Emphasis is on the tendency to act, not the actual acting; what we intend and what we do may be quite different e.g. "I avoid the mentally ill. ${ }^{(16)}$ Here comes this importance of understanding the current attitudes of those who provide services to people with emotional problems. It is estimated that at least 33\% of all general medical patients have a diagnosable mental health problem and about 50-60\% of general hospital inpatients suffer from significant psychological dysfunction as a primary problem or secondary to a diagnosed medical illness ${ }^{\left({ }^{(17)}\right.}$ Here comes the need for early referral to psychiatric services where the nurse's role in this regard is being increasingly recognized. ${ }^{(18)}$

Studying the knowledge and attitudes of nursing staff on this topic is important as they directly deal with patients and their relatives, providing mental health care along with general care to the physically and psychologically ill patients-during which they disseminate health information. ${ }^{(9)}$ Likewise nurses negative attitude is a known hindrance for providing quality services to mentally and physically 
ill persons as they constitute the majority of thestaff . $^{(9)}$

Aim of the Study : The aims of this study

1. Assess the level of nurses' knowledge about mental illness in mental health and general hospitals.

2. Determine nurses' attitudes about mental illness in mental health and general hospitals.

\section{Materials \& Method}

\section{Research design:-}

The present study follows

a descriptive design.

\section{Setting:-}

1-The study was conducted at the Psychiatric Department of Tanta University Hospital and Tanta Mental Health hospital. The latter is affiliated to the Ministry of Health. These two hospitals serve three governorates, namely ElGharbeya, El-Menofeya, and Kafr-ElSheikh. They both have a capacity of 80 beds for psychiatric patients distributed on eight wards (four for males and four for females).

2-Tanta University students' Hospital under the supervision and direction of Tanta University with a capacity of 180 beds and provides health care to university students, school university employees.

\section{Subjects:-}

The study subjects included all available nurses working in the above mentioned settings at the time of data collection. The total number of subjects was (280 nurses) 50 nurses from Tanta Mental Health Hospital, 30 nurses from the psychiatric department of Tanta University Hospital and 200 nurses from Tanta University students' hospital.

Tools of the study: The data were collected using the following tools:

\section{Tool (1) :- The questionnaire that assess knowledge about mental illness. It consisted of two parts:-}

Part one:Socio-demographic

characteristics namely (age, sex, level of education, marital status) as well as the clinical experience of the studied nurses that included: years of experience, previous study of psychiatric nursing, previous training in mental health hospital Part two: The questionnaire sheet to assess knowledge about mental illness. This tool was developed by the researcher based on literature review questionnaire sheet contains 33 close ended questions about mental illness, definition, causes, signs and symptoms, curability as well as the sources of these information. Nurses asked to respond to these questions with "Yes" or "No". The questionnaires were total score ranged between 0-33. 


\section{Tool (2):- Community Attitudes}

toward the Mental Illness Scale (CAMI).

The community attitudes towards mental illness was developed by Taylor et al., (1979) 77\&Taylor and Dear (1981) ${ }^{(19)}$. The CAMI was originally developed for use with general population but has been used with various samples of mental health professionals, including Psychiatrists, nursing and medical staff.

The scale is composed of four attitudinal subscales:

(1) Authoritarianism (10 items): is a view that people with mental illness are inferior and require coercive approach.

(2) Benevolence (10 items): is a sympathetic view of those experiencing mental health problems, based on humanistic principles.

(3) Social restrictiveness (10 items): is a view that people with mental illness are a threat to society.

(4) Community mental health ideology (10 items): a view that support the therapeutic value of the community and acceptance of de-institutionalized care. The scale is self report that consists of 40 statements each necessitating a response as to the level of agreement / disagreement on 5 point liker scale ranging from (1) strongly disagrees to (5) strongly agrees for positive statements and (1) strongly agree to (5) strongly disagree for negative statements.

\section{Method:}

An official written approval was obtained from the head of the Psychiatric department at Tanta University Hospital, Tanta Mental Health Hospital, and Tanta University Student' Hospital.

The study tools were tested for translation and content validity by a group of five experts in the psychiatric medicine and psychiatric nursing field.

The study tools were reliability tested using a test re-tested method (alpha reliability $=0.780$-test-retest

reliability $=0.880$ ).

An oral consent was obtained from the nurses after explanation of the purpose and importance of the study.

The pilot study: A pilot study was carried out before embarking on the field of work, to ascertain the clarity and applicability of the study tools and to identify obstacles that might be faced during data collection. The pilot study was conducted on 25 nurses (20 nurses from the University Students' Hospital and 5 nurses from the Mental health Hospital). These nurses were excluded from the actual study subjects. According to the pilot study results the necessary modifications were done. 


\section{The actual study:}

Nurses on each hospital were contacted on individual basis. The forms of the study tools were explained to the nurses and they were reassured that all information will be confidential and used only for the purpose of the study. Nurses were then asked to respond in privacy and in the presence of the researcher. This was usually done during the afternoon and evening shifts where the work loud on nurses is expected to be low. The time required for filling the tools ranged from 20-30 minutes. Data were collected during the period from October 2010 -December 2010. Data were then categorized by the researcher, checked and revised by the supervisors of the thesis.

\section{Statistical analysis:}

The collected data were organized, tabulated and statistically analyzed using SPSS software statistical computer package version 17. The number and percent distribution of data was calculated. Chi square was used as a test of significance and when found inappropriate the Fisher exact test was used. Odds ratio was calculated as an estimate of risk with 95\% confidence interval. Correlation between variables was evaluated using Pearson's correlation coefficient.
Significance was adopted at $p<0.05$ for interpretation of results of tests of significance (Dawson and Trapp, 2001). Statistical presentation and analysis of the present study was conducted, using the mean, standard error, student t- test, Chisquare, Linear Correlation Coefficient and Analysis of variance [ANOVA] tests

\section{Results}

Table (1) presents the socio-demographic characteristics of the studied nurses, revealed that the mean age of both study groups (Group I nurses working in general hospital \& Group II nurses working in mental health hospital) $32.66 \pm 6.894 \&$ $28.950 \pm 8.676$ years respectively. Regarding their sex all nurses working in general hospital and about $78.75 \%$ of nurses working in mental health hospital were female. Concerning the nurses' marital status those who were married represent the highest percentage of both studied groups $(71.50 \%$ and $60 \%$ respectively). In relation to nurses' educational level, about two third of nurses in group I and half of nurses in group II had secondary school nursing diploma (67\% \&51.25\% respectively) while $27 \%$ of nurse in group I had university education and $5 \%$ of them had technical institute of nursing but $25 \%$ of nurses working in 
mental health hospital had university education and the rest of them had technical institute of nursing.

Table (2) presents the clinical experience of the studied nurses both working in general hospital (group I) \& in mental health hospital (group II). As for having previous clinical training in mental health hospital about one third of the studied nurses in group I and nearly half of the nurses in group II $(32.50 \% \quad \& 53.75 \%$ respectively) had a previous clinical training in mental health hospital. Concerning previously studying of psychiatric course in their nursing curriculum, the majority of the studied nurses in group I and group II (70.50\% and $91.25 \%$ respectively) confirmed studying psychiatric nursing.

Table (3) reveals the nurses' knowledge about mental illness and their sources. The results showed that all nurses working in mental health hospital and $90.50 \%$ of nurses working in general hospital reported that they had knowledge about mental illness. The most frequent sources of knowledge by nurses working in mental health hospital were "contact with the mentally ill" (90\%), followed by their basic nursing education (77.50\%), and then by psychiatrist $(51.25 \%)$ on the other side the media constituted the most frequent source of knowledge reported by nurses working in general hospital (55\%), followed by their basic nursing edu (46\%) The difference between the two groups regarding their sources of knowledge about mental illness was statistically significant except in friends or relatives $(p>0.05)$

Table (4) shows nurses' knowledge about and attitudes towards mental illness mean scores. Regarding the nurses knowledge about mental illness, one can notice that nurses working in mental health hospital obtained a higher mean score compared to nurses working in general hospital $(21.025 \pm 6.818 \& 17.015 \pm 7.220$

respectively).

In relation to their attitudes towards mental illness, nurses working in mental health hospital obtained a higher mean Score compared to nurses working in general hospital in authoritarianism $(34.263 \pm 5.828$ $\& 30.180 \pm 6.600$ respectively), benevolence $(39.263 \pm 4.434 \& 35.940 \pm 6.849$

respectively), social restrictiveness (34.963 $\pm 5.531 \& \quad 31.910 \pm 5.918$ respectively), community mental health ideology (43.725 $\pm 6.541 \& 39.490 \pm 8.073$ respectively) and total attitude $(152.213 \pm 16.814 \&$

$137.520 \pm 20.458$ respectively).

Statistically significant differences were detected between the two groups regarding 
their knowledge and attitudes towards mental illness, with those working in mental hospital showing higher mean scores.

Table (5) reflects the correlation between nurses' knowledge and attitudes towards mental illness. A significant positive correlation was detected between knowledge and Authoritarianism, benevolence, Social restrictiveness, community mental ideology, and total attitude, which denote that nurses who had a better knowledge were holding more positive attitudes. 
Table (1) Socio-demographic characteristics of the studied nurses $(n=280)$

\begin{tabular}{|c|c|c|c|c|}
\hline \multirow{3}{*}{$\begin{array}{l}\text { Socio-demographic } \\
\text { characteristics }\end{array}$} & \multicolumn{4}{|c|}{ Groups } \\
\hline & \multicolumn{2}{|c|}{$\begin{array}{c}\text { Group I } \\
\text { (nurses working in } \\
\text { general hospital ) } \\
(\mathbf{n}=\mathbf{2 0 0})\end{array}$} & \multicolumn{2}{|c|}{$\begin{array}{l}\quad \text { Group II } \\
\text { (nurses working in } \\
\text { mental health hospital) } \\
(n=80)\end{array}$} \\
\hline & $\mathbf{N}$ & $\%$ & $\mathbf{N}$ & $\%$ \\
\hline \multicolumn{5}{|l|}{ Age } \\
\hline $20-$ & 73 & 36.50 & 64 & 80.00 \\
\hline $30-$ & 93 & 46.50 & 7 & 8.75 \\
\hline $40-$ & 34 & 17.00 & 4 & 5.00 \\
\hline$>50$ & 0 & 0.00 & 5 & 6.25 \\
\hline Range & \multicolumn{2}{|c|}{$20-50$} & \multicolumn{2}{|c|}{$21-58$} \\
\hline Mean \pm SD & \multicolumn{2}{|c|}{$32.66 \pm 6.894$} & \multicolumn{2}{|c|}{$28.950 \pm 8.676$} \\
\hline \multicolumn{5}{|l|}{$\overline{\operatorname{Sex}}$} \\
\hline Male & 0 & 0.00 & 17 & 21.25 \\
\hline Female & 200 & 100.00 & 63 & 78.75 \\
\hline \multicolumn{5}{|l|}{ Marital status } \\
\hline Single & 38 & 19.00 & 29 & 36.25 \\
\hline Married & 143 & 71.50 & 48 & 60.00 \\
\hline Divorced & 16 & 8.00 & 1 & 1.25 \\
\hline Widow & 3 & 1.50 & 2 & 2.50 \\
\hline \multicolumn{5}{|l|}{ level of education } \\
\hline $\begin{array}{l}\text { Secondary school nursing } \\
\text { diploma }\end{array}$ & 134 & 67.00 & 41 & 51.25 \\
\hline Technical nursing institute & 10 & 5.00 & 19 & 23.75 \\
\hline University education & 56 & 27.50 & 20 & 25.00 \\
\hline
\end{tabular}


Table (2) Clinical experience of the studied nurses $(n=280)$

\begin{tabular}{|c|c|c|c|c|}
\hline \multirow{3}{*}{$\begin{array}{l}\text { Clinical experience of the } \\
\text { studied nurses }\end{array}$} & \multicolumn{4}{|c|}{ Groups } \\
\hline & \multicolumn{2}{|c|}{$\begin{array}{l}\text { Group I(nurses working } \\
\text { in general hospital) } \\
(n=200)\end{array}$} & \multicolumn{2}{|c|}{$\begin{array}{l}\text { Group II(nurses } \\
\text { working in mental } \\
\text { health hospital) } \\
(n=80)\end{array}$} \\
\hline & $\mathbf{N}$ & $\%$ & $\mathbf{N}$ & $\%$ \\
\hline \multicolumn{5}{|l|}{ Years of experiences } \\
\hline $1-$ & 45 & 22.50 & 52 & 65.00 \\
\hline $6-$ & 17 & 8.50 & 13 & 16.25 \\
\hline $11-$ & 52 & 26.00 & 11 & 13.75 \\
\hline 16- & 50 & 25.00 & 1 & 1.25 \\
\hline$>20$ & 36 & 18.00 & 3 & 3.75 \\
\hline Mean \pm SD & \multicolumn{2}{|c|}{$13.57 \pm 7.48$} & \multicolumn{2}{|c|}{$6.36 \pm 5.69$} \\
\hline \multicolumn{5}{|c|}{ previous clinical training in mental health hospital } \\
\hline Yes & 65 & 32.50 & 43 & 53.75 \\
\hline No & 135 & 67.50 & 37 & 46.25 \\
\hline \multicolumn{5}{|c|}{ previous study of psychiatric nursing in the study of nursing } \\
\hline Yes & 141 & 70.50 & 73 & 91.25 \\
\hline No & 59 & 29.50 & 7 & 8.75 \\
\hline
\end{tabular}


Table (3) Sources of nurses' knowledge about mental illness $(\mathbf{n = 2 8 0})$

\begin{tabular}{|c|c|c|c|c|c|c|}
\hline \multirow{3}{*}{$\begin{array}{c}\text { Sources of nurses' } \\
\text { knowledge about mental } \\
\text { illness }\end{array}$} & \multicolumn{6}{|c|}{ Groups } \\
\hline & \multicolumn{2}{|c|}{$\begin{array}{l}\text { GroupI(nurses } \\
\text { working in } \\
\text { general } \\
\text { hospital ) } \\
(\mathbf{n}=200)\end{array}$} & \multicolumn{2}{|c|}{$\begin{array}{l}\text { Group II(nurse } \\
\text { working in } \\
\text { mental health } \\
\text { hospital) } \\
(n=80)\end{array}$} & \multicolumn{2}{|c|}{ Chi-square } \\
\hline & $\mathbf{N}$ & $\%$ & $\mathbf{N}$ & $\%$ & $\mathbf{X}^{2}$ & P-value \\
\hline \multicolumn{7}{|c|}{ Do you have knowledge about mental illness? } \\
\hline Yes & 181 & 90.50 & 80 & 100.00 & \multirow{2}{*}{8.153} & \multirow{2}{*}{$0.004 *$} \\
\hline No & 19 & 9.50 & 0 & 0.00 & & \\
\hline \multicolumn{7}{|c|}{ Sources of nurses' knowledge about mental illness } \\
\hline Basic nursing education & 92 & 46.00 & 62 & 77.50 & 12.209 & $<0.001 *$ \\
\hline Reading books & 14 & 7.00 & 28 & 35.00 & 35.137 & $<0.001 *$ \\
\hline Friends and relatives & 24 & 12.00 & 8 & 10.00 & 0.226 & 0.635 \\
\hline Media (net,Tv,magazines) & 110 & 55.00 & 25 & 31.25 & 5.111 & $0.024 *$ \\
\hline From doctors & 11 & 5.50 & 41 & 51.25 & 79.090 & $<0.001 *$ \\
\hline Work shop and seminars & 5 & 2.50 & 31 & 38.75 & 67.020 & $<0.001 *$ \\
\hline $\begin{array}{l}\text { Contact with mentally ill } \\
\text { patients }\end{array}$ & 8 & 4.00 & 72 & 90.00 & 207.088 & $<0.001 *$ \\
\hline
\end{tabular}

Note: Answers are not mutually exclusive 
Table(4) Nurses about Knowledge .attitudes to wardes mental illness

\begin{tabular}{|c|c|c|c|c|c|c|c|c|}
\hline \multirow{3}{*}{$\begin{array}{l}\text { Nurses' knowledge and attitudes } \\
\text { towards mental illness }\end{array}$} & \multicolumn{8}{|c|}{ Groups } \\
\hline & \multicolumn{3}{|c|}{$\begin{array}{c}\text { Group I(n=200) } \\
\text { Nurses working in } \\
\text { general hospital }\end{array}$} & \multicolumn{3}{|c|}{$\begin{array}{c}\text { Group II(n=80) } \\
\text { Nurses working in } \\
\text { mental health } \\
\text { hospital }\end{array}$} & \multicolumn{2}{|c|}{ T-test } \\
\hline & Mean & \pm & SD & Mean & \pm & SD & $\mathrm{T}$ & P-value \\
\hline I-Knowledge & 17.015 & \pm & 7.220 & 21.025 & \pm & 6.818 & 4.265 & $<0.001^{*}$ \\
\hline \multicolumn{9}{|l|}{ II-Subscales of attitude } \\
\hline a. Authoritarianism & 30.180 & \pm & 6.600 & 34.263 & \pm & 5.828 & 4.830 & $<0.001^{*}$ \\
\hline b. Benevolence & 35.940 & \pm & 6.849 & 39.263 & \pm & 4.434 & 4.013 & $<0.001^{*}$ \\
\hline c. Social restrictiveness & 31.910 & \pm & 5.918 & 34.963 & \pm & 5.531 & 3.971 & $<0.001^{*}$ \\
\hline $\begin{array}{l}\text { d. Community mental health } \\
\text { ideology }\end{array}$ & 39.490 & \pm & 8.073 & 43.725 & \pm & 6.541 & 4.175 & $<0.001^{*}$ \\
\hline III- Total attitude & 137.520 & \pm & 20.458 & 152.213 & \pm & 16.814 & 5.698 & $<0.001^{*}$ \\
\hline
\end{tabular}

Table (5) Correlation between the studied nurses' knowledge and attitudes towards mental illness $(n=280)$

\begin{tabular}{|c|c|c|}
\hline \multirow{2}{*}{ Nurses' attitudes towards mental illness } & \multicolumn{2}{|c|}{ Knowledge } \\
\hline & $\mathbf{r}$ & P-value \\
\hline \multicolumn{3}{|l|}{ I-Subscales of attitude } \\
\hline a-Authoritarianism & 0.305 & $<0.001^{*}$ \\
\hline b-Benevolence & 0.198 & $<0.001^{*}$ \\
\hline c-Social restrictiveness & 0.272 & $<0.001 *$ \\
\hline d-Community mental health ideology & 0.290 & $<0.001 *$ \\
\hline II- Total attitude & 0.350 & $<0.001^{*}$ \\
\hline
\end{tabular}




\section{Discussion:}

A persistent negative attitude and social rejection of people with mental illness have prevailed throughout history in every social and religious culture. Poor knowledge and negative attitude towards mental illness threaten the effectiveness of patient care and rehabilitation, this poor and inappropriate view about mental illness and negative attitude about mentally ill can inhibit the decision to seek help and provide proper holistic care. Better knowledge is often reported to result in improved attitudes towards people with mental illness and a belief that mental illness are treatable which can encourage early treatment seeking and promote better outcomes $^{(19) .}$

The results of the current study indicated that, nurses working in mental health hospital have better knowledge about mental illness compared to those working in general hospitals. Needless to say that, nurses working in mental health hospital are always in interaction with mentally ill patients and psychiatrists where they had an opportunity to attend team conferences and engage in activities with patients. On the other hand, nurses working in general hospitals are missing all the previously mentioned opportunities and tend to give more attention to physical problems rather than the emotional problems associated with physical illness. This explains the deficiency in knowledge about mental illness among general nurses. This supported by Keshavan \& Sriram(1991) ${ }^{(19)}$ who mentioned that general nurses had less than satisfactory mental health knowledge and skills. This fact was further supported when nurses were asked about the source of their knowledge. The present study revealed that "contact with the mentally ill "constituted the most frequently reported source of knowledge about mental illness among nurses working in mental health hospitals followed by basic nursing education and then by psychiatrists", while the "media " constituted the most frequently reported sources of knowledge about mental illness among nurses working in general hospitals followed by basic nursing education. This indicates the importance of improving image of the mentally ill patients and disseminating accurate information about mental illness by the mass media; the primary source of 
information for many people. This comes in agreement with Shyangwa \& Singh, $(2003)^{(9)}$ who found that the majority of their studied subjects obtained their information about mental illness from" seeing the mentally ill persons followed by communication with doctors and their reading newspaper. This finding indicates that, nurses working in general hospitals are in need for educational programs and training to increase their skills \& knowledge about mental illness. This is also important because many studies have shown that there is high rate of psychological problems among patients with physical illness at inpatient and outpatient levels.

Working in mental health hospital lead to a significantly more positive total attitude in nurses than thos working in general hospital. This may be attributed to their experience in the psychiatric field \& the multiple sources of knowledge about mental illness around them. In this respect, many studies showed that interpersonal contact with mentally ill patients is associated with positive attitude towards mental illness. In the same direction a study done by Bjorkman, (2008) ${ }^{(20)}$ noted that, nurses working in psychiatric settings have more positive attitudes than those working in somatic care. This is in contrary to a study done by Buchanana et al., (1992) (21) who found that staff working at psychiatric settings had a negative attitude toward mentally ill patient. In between Gateshill \& Wattis, (2011) ${ }^{(22)}$ found that Mental healthcare professionals and non-mental healthcare professionals show broadly similar attitudes and a similar degree of empathy towards people with a mental disorder .

As for the relationship between nurses' knowledge about mental illness and their total attitude, several studies revealed that positive attitudes towards individuals with a mental illness are correlated with knowledge about mental illness ${ }^{(19,22) .}$ The current study found that there was a significant positive relationship between knowledge and total attitude; this means that the better the knowledge the more positive the attitude. This highlights the importance of knowledge in the formation of positive attitude. In the same direction, Wolf et al., (1996) ${ }^{(23)}$ stated that negative attitudes have been attributed to a lack of knowledge. This is also supported by Ahmad \& Rawiyah, (2004) ${ }^{(24)}$ concluded that knowledge seems to have an effect on 
Inculcating greater tolerance of mental illness. On the contrary, a study by Addison, (2004) ${ }^{(25)}$ who stated that the relationship between knowledge and attitudes is not clear.

Concerning the relationship between the sources of nurses' knowledge and attitudes toward mental illness, the finding of the present study revealed a statistical significant relation between attitudes towards mental illness and nurses' sources of information. The most positive attitude was that related to "contact with mentally ill" and the least positive attitude was that related to the "media" with a mean it seems that media plays a major role in contributing to mental illness stigma via the images they portray of characters with mental illness as well as the misinformation communicated, inaccurate use of psychiatric terms, and unfavorable stereotypes of people with mental illness. This is consistent with Couture \& Penn, $(2003)^{(26)}$ who asserted that both personal and professional contact is associated with increased positive attitudes towards mental illness .Similarly, a study done by Desforges et al., $(1991)^{(27)}$ found that the more intimated the experience with a mentally ill the more positive were the attitude . This supported by Thrnicroft, $(2006)^{(28)}$ who mentioned that direct contact with people with mental illness is one way of changing attitude. On the contrary, a study by Callaghan et al., $(1997)^{(29)}$ \& Al-Adawi \& Al Ghafry, $(2002)^{(30) .}$ mentioned that previous contact with mental illness had no significant effect on the attitudes towards mental illness .

\section{Recommendations:}

1- Strategies in basic nursing education should concentrate on knowledge about mental illness and equally on the affective domain and communication skills to encourage the attitude shaping

2- In-service training and educational program about the nature of mental illness and mentally ill patients for nurses working in mental hospital should be implemented to provide better understanding and to ensure that patients are treated with dignity and respect in a therapeutically. effective and ethically sound environment.

3- In-service training and educational program for nurses working in general hospitals as they frequently need while consequences of physical illness. 
4- Mass media can be used to upgrade and/or correct knowledge of the community about mental illness because media are the primary source of information for many people.

5-Attitudes and interest of the nurses must be considered when recruiting them in mental health hospital

\section{Reference}

1-Plummer S, Taverner A, Gray R, Lee S, Payne F \& Knight Districtnurses' involvement and attitudes to mental health problems: a three-area cross-sectional study. Journal of Clinical Nursing. 2005;14(5):976-985.

2-Encyclopedia of Mental Illness.

Definition and classification of mental illness.2010 (cited 2010 22-2).Available at: http://plato.stanforddu/entries/mental-

illness

3-Mohr WK. Psychiatric Mental Health Nursing 7th ed. Philadelphia: Lippincott Co, 2009;. 5-15.

4-Videbeck S L. Psychiatric-Mental Health Nursing. 4th ed. Philadelphia: Lippincott Co, 2008; 4-14

5-Mohr W K. Psychiatric Mental health Nursing $7^{\text {th }}$ ed. Philadelphia: Lippincott Co,2009; 4-1
6- Shives LR and Isaacs A .Basic concept of Psychiatric Mental Health Nursing. $5^{\text {th }}$ ed. New York; Lippincott Co, 2002; 3-15 7-Link BG, Phelan JC .Conceptualizing stigma. Annual Reviews in sociology 2001; 27: 363-385

8-Coffman E. Stigma : Notes on the management of spoiled identity. PrenticHall, Englewood Cliffs. 1963

9-Shyangwa P M, Singh S, khandelwal S K.Knowldge and Attitude about mental illness among nursing staff. Journal of Nepal medical association, 2003; 42(5):21. 10-Wahl O, cohen A E. Attitudes of mental health professionals about mental illness. Journal of community psychology.2010; 38(2):49-62

11-Gureje O, Ephraim O,victor O . Community study of Knowledge and attitude to mental illness. The British Journal of Psychiatry, 2005; 186(4): 436-.

12-Fontaine K 1 Mental Health Nursing $.6^{\text {th }}$ ed .London; Pearson, 2009; 3-19

13-Emrich T.C, Moore G .Positive attitude: an essential element for effective care of people with mental illnesses. Journal of Psychosocial Nursing and Mental Health Services 2003; 41(5):18-25. 
14-Schultz B, Angermeyer MC Subjective experiences of stigma .A focus group study of schizophrenic patients, their relatives and mental health professionals. Social science and Medicine. 2003;56(2):229-312 15-MclaughlnC.Causality nurses' attitudes towards to attempted suicide .Journal of advanced nursing 1994; 20(3): 1111-1118. 16-Hamaideh S H, Mudalla R .Attitudes of Jordanian nursing students towards mental illness: the effect of teaching and contact on attitudes change.2009; 30(11):705-711

17-Hadley A personality characteristics and attitudes toward mental illness in general hospital nurses. University of Miami (Florida) 1987.

18-Taylor S M, Dear M J.scaling community attitude toward the mentally ill. 1981; 7(2)225-240

19- Keshavan K, Srirant SL. Mental health knowledge and skills of general hospital nursing staff: 0an exploratory study. Int J Soc Psychiatry. 1991; 37(4):280-284.

20-Bjorkman T. Attitudes towards people with mental illness: a cross sectional study among nursing staff in psychiatric and somatic care. Scandinavian Journal of caring sciences 2008; 22:170-177.
21-Bucannan A \& Bhugra D. Attitude of the medical profession to psychiatry. Acta Psychiatrica Scandinavica 1992; 85: 1-5. 22-Gateshill G, Wattis J. Attitudes towards mental disorders and emotional empathy in mental health and other healthcare professionals. The Royal College of Psychiatrist 2011; 35: 101-105.

23-Wolff G Community Knowledge of Mental illness and Reaction to Mentally Ill People. British Journal of Psychiatry 1996; 168:191-198.

24-Ahmad H, Rawiyah R Attitudes of Paramedics towards Mentally III Patients. Malaysian Journal of Psychiatry. 2004; 12(1): 1 .

25-Addison SJ .Factors involved in the formation attitudes towards those who are mentally ill. Social psychiatry and psychiatric epidemiology 2004; 49(6): 228-234.

26-Penn DL, Couture SM . Interpersonal contact and the stigma of mental illness: A review of literature. Journal of mental health 2003; 12( 3): 291-305.

27-Desforges DM, Lord CG, Ramsey SL.,. Effects of structured cooperative contact on changing negative attitudes toward 
stigmatized social groups. Journal of Personality and Social Psychology 1991; 60(4): 531-44.

28-Thornicroft G, Brohan E, Kassam A, Lewis-Holmes E Reducing Stigma and Discrimination: candidate interventions. International Journal of Mental Health Systems 2008 ; 2(1) :45

29- Callaghan P, Shan SC Attitudes towards mental illness: testing the contact hypothesis among Chinese student nurses in Hong Kong 1997; 26(3):3-40.

30- Al-Adawi S, Al Ghafry D. Perception of and attitudes towards mental illness in Oman. International journal of social psychiatry. 2002;(48) 4:305-317 